Aksaray University
Journal of Science and Engineering
e-ISSN: $2587-1277$ Aksaray J. Sci. Eng.
http://asujse.aksaray.edu.tr

Research Article

\title{
Correlation Analysis of Flexible Road Pavement Surface Condition and Load Bearing Capacity of Subgrade Soil
}

\author{
Paul Terkumbur Adeke ${ }^{1, *}$, Ianna Moris Kanyi ${ }^{1}$, Maryam Yusuf Olawuyi ${ }^{2}$ \\ ${ }^{1}$ Department of Civil Engineering, College of Engineering, Federal University of Agriculture Makurdi, Makurdi, \\ Benue State, Nigeria. \\ ${ }^{2}$ Department of Civil Engineering, Federal Polytechnic Offa, Offa, Kwara State, Nigeria.
}

-Received Date: Jun 23, 2021

-Accepted Date: Jul 08, 2021

-Published Online: Sep 25, 2021

\begin{abstract}
Following the continuous deterioration of flexible road pavements on Federal Highways in Northern Nigeria, which in some quarters is attributed to poor structural capacity of the subgrade soil or design and workmanship; this study examined the relationship between the instantaneous surface condition of flexible road pavement and the California Bearing Ratio (CBR) values of the corresponding subgrade soils. An investigation of road surface condition was carried out on $60 \mathrm{~km}$ length of the Zaria - Kaduna Federal Highway in Northern Nigeria. Experimental results on the mechanical properties of the corresponding subgrade soils of road segments measured at Chainages were obtained from the Nigeria Federal Ministry of Power, Works and Housing (FMPWH). The primary data used by the study were measured as quantities of surface area distresses along the site which included; cracks, potholes, rutting and edge failure, while secondary data from the FMPWH database included; natural moisture content, maximum dry density, specific gravity, liquid limit, plastic limit, liquidity index, optimum moisture content, California Bearing Ratio (CBR), percent of soil particles passing \#200 sieve and AASHTO classification of the subgrade soil. A Pearson correlation analysis between the road pavement surface condition and the CBR value of the subgrade soil at $95 \%$ Confidence Level using a 1-tailed statistics for the test hypothesis revealed that, there was no dependency between the pavement surface condition and the corresponding CBR property of the subgrade soil.
\end{abstract}

\section{Keywords}

Highway Pavement, Subgrade soil, California Bearing Ratio (CBR), Resilience Modulus, Pavement distress.

\footnotetext{
"Corresponding Author: Paul Terkumbur Adeke, : adeke.pt@outlook.com (iD $\underline{0000-0003-2939-8465}$
} 


\section{INTRODUCTION}

Flexible road pavement is a common highway facility in Nigeria. This is due to its relatively cheap cost of construction and maintenance practice [1-2]. The performance and life cycle of highway road pavement depend on several factors ranging from environmental conditions, traffic load, material properties, age of pavement, original design of pavement structure, construction quality - workmanship, road geometry and maintenance policy over time [2-4].

The structure of a flexible road pavement is a combination of some elastic unbound layers of soil materials that help distribute traffic load downward into the sub-soil without any appreciable permanent deformation. The basic layers that constitute a typical flexible road pavement structure include; the wearing course, sub-base, base and subgrade soils [5]. Highway pavements are usually built on sub-soil materials with the subgrade soil being the natural bed upon which the entire pavement structure lays. The strength properties of the subgrade soil measured as load bearing capacity-California Bearing Ratio (CBR) also known as its stiffness affects the serviceability and life cycle of the road pavement to a great extent [6-8]. In simple terms, the subgrade soil is referred to as the foundation of a road pavement structure [9-10]. In pavement analysis and design for efficient services, materials with sufficient strength properties or load bearing capacity are required to be placed above the natural ground-subgrade soil as the wearing course, sub-base and base to help absorb the imposed traffic load before it gets to the subgrade layer since subgrade soils are usually weak and could easily produce rutting or permanent deformation when subjected to relatively high wheel load beyond its strength [11$13]$.

Due to its complex nature and proneness to actions of external damaging factors, the comprehensive investigation of road pavement failure in most cases is a difficult task. Though the analysis and design of pavement structure is generally aimed at providing an economical structure with sufficient strength over time to serve, by resisting traffic load and the effects of other damaging factors such as weather condition, age and workmanship within appreciable time period [10]; the failure of road pavement before its designed service life or at the end of its service time is inevitable. In most cases, the pavement structure falls short of its service time. This therefore necessitates strict adherence to the Nigerian General Specifications for Design of Roads and Bridges [14] which is the product of long term investigation of road behaviour to help improve road pavement performance.

The failure of road pavement manifests as distresses such as fatigue cracks, rutting or permanent deformation, edge failure and potholes which reduce the efficiency or serviceability of the 
highway occur [3]. The severity and frequency of occurrence of these distresses or defects affects the surface condition and the entire performance of the highway [3]. Previous studies have established that the initiation and propagation rate of pavement distress is a direct function of the subgrade soil type, environmental conditions and strength properties of the soil $[8,10$, 15]. The major strength property or structural capability of pavement structure is measured as the resilient modulus or stiffness characteristics of the subgrade soil. The Resilient Modulus of subgrade soil is simply the measure of the elastic behaviour of the soil under the influence of traffic load and other factors. Its magnitude varies with respect to soil type, be it fine-grain or granular [16]. The behaviour of subgrade soil is basically a function of its moisture content, density and gradation of the soil [7, 9, 17-20].

Generally, the mechanical behaviour of an in situ pavement subgrade soil majorly depends on traffic load imposed on it, and the environmental characteristics among other factors such as; the stress state, density, particle size distribution, particle shape, fine content, number of load cycles and moisture content. The moisture content depends on the rate of pore suction which is a measure of the confining pressure, deviator stress and the matric suction as they affect the resilient modulus of the subgrade [7].

The particle size distribution of the subgrade soil is also significant to the mechanical properties of the subgrade soil. It defines the ratio of fine to granular content of the soils, which influences its general strength properties and consequently the resilient modulus [7]. Park et al. [15] stated clearly that the percent passing \#200 sieve, moisture content and the maximum dry density are the most significant soil properties that affects the resilient modulus of the subgrade soil. Though the resilient modulus parameter in most cases is not obtained from laboratory tests directly, previous studies have developed mathematical models that are useful for estimating Resilient Modulus $\left(\mathrm{M}_{\mathrm{R}}\right)$ values from the California Bearing Ratio (CBR) value due to its significant relevance to pavement analysis and design $[9,16]$.

Based on findings of previous studies, Rahim [9] reiterates that for fine-grain subgrade soils, increase in moisture content of the soil reduces its strength property, while increase in density property increases the bearing capacity. Also, the strength properties of granular soils depends on the confining pressure, the gradation degree of saturation and the degree of compaction of the soil.

Based on reviewed literatures, several factors are responsible for the present poor state of road pavement in Nigeria, particularly Northern Nigeria. But it is not very certain why the Federal Highways tend to fail earlier than their actual design life period. 
This study therefore aims at investigating the correlation between road pavement surface condition and CBR of corresponding subgrade soil along $60 \mathrm{~km}$ of the Zaria - Kaduna federal highway. The objectives are to investigate the road pavement surface condition, examine structural strength of the subgrade soil and to determine correlation between the road surface condition and corresponding structural strength of the subgrade soil.

\subsection{Research Question}

Does the structural strength - CBR value of subgrade soil affect the surface condition of flexible road pavement in Northern Nigeria?

\subsection{Hypotheses:}

$\mathrm{H}_{0}$ : There is correlation between surface condition of flexible road pavement and the CBR value (structural strength) of the subgrade soil

$\mathrm{H}_{1}$ : There is no correlation between surface condition of flexible road pavement and the CBR value (structural strength) of the subgrade soil

\section{MATERIALS AND METHODS}

\subsection{Description of Study Area}

This study considered the Zaria - Kaduna Federal Highway in Northern Nigeria. The road corridor is a $60 \mathrm{~km}$ length Federal Highway located within the North-West region of Nigeria. It is the major route that connects the North-Central and North-West regions of Nigeria running through Kaduna State. Zaria town is located on Latitude $11^{\circ} 5^{\prime} 7.83^{\prime \prime N}$ and Longitude $7^{\circ} 43^{\prime} 18.22^{\prime \prime E}$, while Kaduna town is located on Latitude $10^{\circ} 30^{\prime} 37.67 " \mathrm{~N}$ and Longitude $7^{\circ} 24^{\prime} 59.42 " \mathrm{E}[21]$.

\subsection{Data Collection}

\subsubsection{Primary data}

Field work was carried out to obtain data on pavement distress condition at the site. This involved the identification of common types of pavement surface defects and measuring affected surface areas within segments bounded by defined chainages measuring $4 \mathrm{~km}$ apart. The common defects included; fatigue cracks, rutting or permanent deformation, edge failure, and potholes. The measuring instruments used included; meter rule for gauging and measurement of elevations caused by deformations leading to rutting distress. A steel tape was used for measuring linear distances for the computations of affected surface area by each type of surface defect. Other physical road facilities such as drainage and road shoulder conditions were also inspected. Common defects on the investigated site were as presented in Fig. 1. 

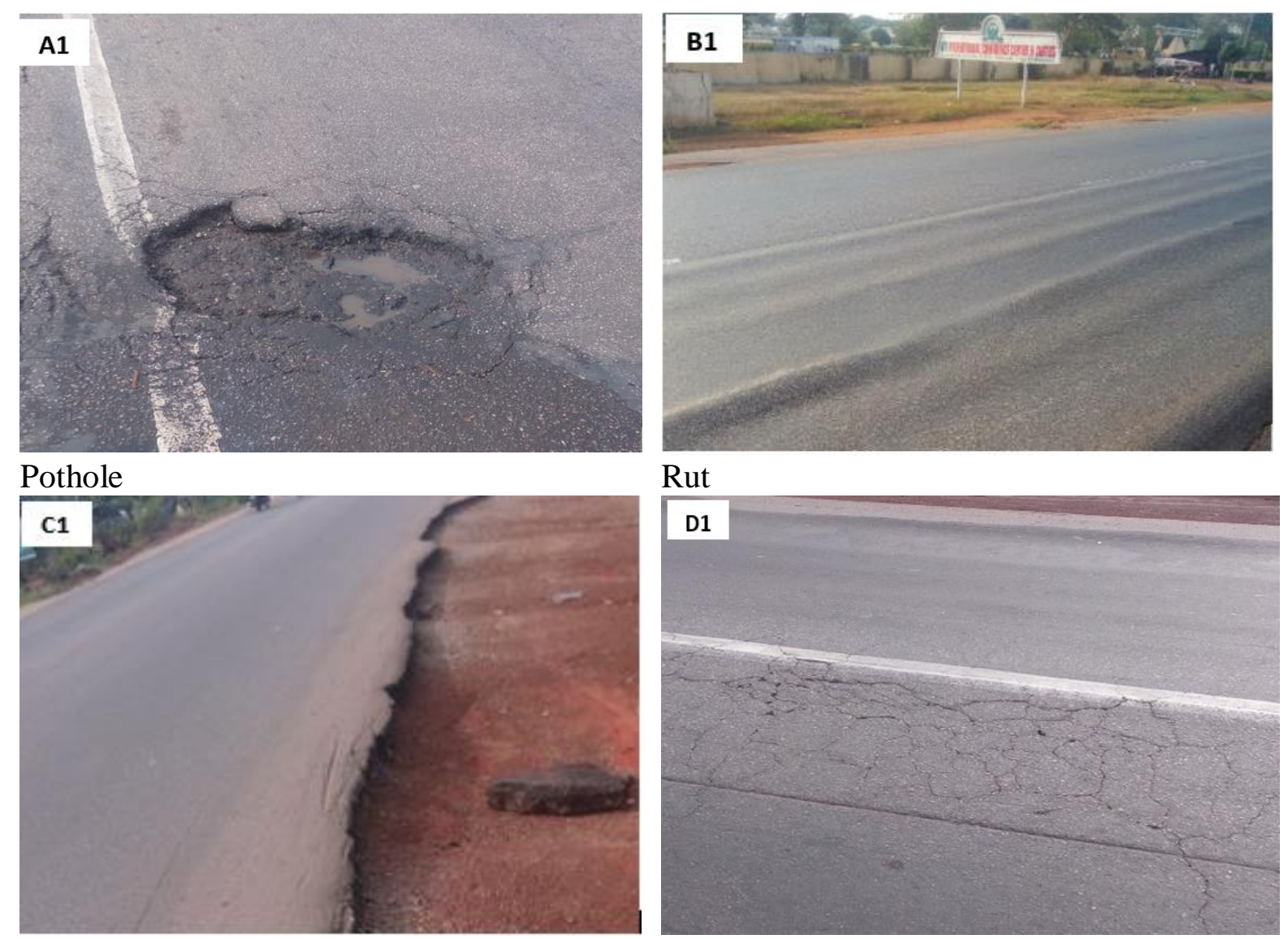

Edge Failure

Fatigue Crack

Figure 1. Some Common Pavement Surface Defects

Summary of the procedure used for computing affected surface area of road pavement is as follows;

Step 1: Carry out a classified collation of various defects according to affected surface area.

Step 2: Sum up the total quantity of each defects type within a given road segment

Step 3: Determine percentage area of the given type of defect using Eq. 1.

Area of Defect $(\%)=\frac{\text { Total Area of Defects }}{\text { Area of Segment }} \times 100$

\subsubsection{Secondary data}

Data from road pavement condition evaluation unit of the Federal Ministry of Power, Works and Housing Nigeria corresponding to the site were obtained and considered for this study. The report indicated results of laboratory tests for subgrade soil which included the following.

\subsubsection{Moisture Content}

This is the total amount of water found in a soil sample. It has direct impact on the bearing capacity or strength and stability properties of the soil. When contained in its natural state, it is referred to as natural moisture content. It is expressed as the ratio of the mass of water in wet soil sample to the mass of dried soil [22]. The wet soil sample was oven dried for a period of 24 hours at a temperature of $110^{\circ} \mathrm{C}$ for the purpose of the experiment as stated in ASTM D 
2216-92 [23]. The formula used for estimating natural moisture content is as presented in Eq.

2.

$w=\frac{M w}{M s} \times 100$

where, $\mathrm{w}$ is the natural moisture content, $\mathrm{Mw}$ is the mass of water in wet soil and Ms is the mass of the dried soil sample.

\subsubsection{Maximum dry density}

This is also known as the zero air void density. It is the density of soil sample when compacted at optimum moisture content, its measures the mass of solid only per unit volume of soil sample using a standard energy level of compaction. The laboratory test involved the use of a cylindrical mould and standard compactive effort on a three equal layer of soil which was compacted using $2.5 \mathrm{~kg}$ mass rammer falling freely through $300 \mathrm{~mm}$ for 27 blows based on the the proctor test procedure as stated in Craig [22] and BS 1377 [24]. The maximum dry density was therefore obtained from a plot of dry density against water content as the intercept of optimum water content with dry density on the curve. The maximum dry density is estimated using Eq. 3.

$\rho_{d}=\frac{G_{s}}{1+w G_{s}} \rho_{w}$

where, $\rho_{d}$ is the dry density of the soil, $G_{s}$ is the specific gravity, w is the optimum moisture content and $\rho_{w}$ is the density of water.

\subsubsection{Specific gravity test}

Specific Gravity of subgrade soil samples at various chainages were measured based on specifications stated in BS 1377 [24]. It was calculated using Eq. 4.

$G s=\frac{W_{2}-W_{1}}{\left(W_{4}-W_{1}\right)-\left(W_{3}-W_{2}\right)}$

where, Gs = Specific Gravity, $\mathrm{W}_{1}=$ weight of bottle $(\mathrm{g}), \mathrm{W}_{2}=$ weight of bottle + dry soil $(\mathrm{g})$, $\mathrm{W}_{3}=$ weight of bottle + soil + water $(\mathrm{g})$ and $\mathrm{W}_{4}=$ weight of bottle + water $(\mathrm{g})$

\subsubsection{Atterberg limits}

These are also known as index properties of the subgrade soil. They include liquid limits, plastic limits and plasticity index. The experiment used procedure stated in the Test 1 (A) BS 1377: Part 2 [24] on the subgrade soil.

\section{Liquid Limit}

This is the minimum moisture content of the soil sample measured in percentage at which it could change from liquid to plastic state or simply the minimum moisture which allows the soil 
to flow under its own weight. Its value is usually obtained as the moisture content that correspond to 25 blows on the liquid limit graph.

\section{Plastic Limit}

This is the minimum water content at which the soil just begins to crumble when rolled into a thread of approximately $3 \mathrm{~mm}$ diameter.

\section{Plasticity Index}

This parameter is estimated using the liquid limit and plastic limit values based on Eq. 5 .

$P I=L L-P L$

where, PI = Plasticity index, $\mathrm{LL}=$ Liquid limit and PL $=$ Plastic limit

\subsubsection{Optimum moisture content}

This is the amount of water content that corresponds to the maximum dry density of the soil sample deduced from the dry density/moisture content plot.

\subsubsection{California Bearing Ratio (CBR)}

This test was developed in California in the USA in 1930's as an index test used for estimating strength property of soils compared to a standard sample of rock. The parameter was measured using procedures stated in BS 1377: Part 4 [24] for a standard mould using $2.5 \mathrm{~kg}$ rammer falling through a height of $300 \mathrm{~mm}$ on three layers each being given 62 blows followed by 48 hours curing before the test was carried out. Its value was estimated for soaked samples using Eq. 6 which define worst case scenario in this investigation since the property variability of subgrade soils is very high [8].

$C B R=\frac{\text { Measured Load }}{\text { Standard Load }} \times 100$

\subsubsection{Particle size distribution - percent passing \#200 sieve}

This is an explanatory variable used for the classification of soil particle sizes into very coarse (boulders and Cobbles), coarse (Gravel and sand) and fine (silt, clay and organic) grain soils. The description is such that when more than $35 \%$ of the soil grained is retained on the \#200 sieve, the soil is classified as being course, otherwise, it is defined as a fine grained soil [25].

\section{RESULTS AND DISCUSSION}

The distribution of total surface area of various pavement defects which included cracks, potholes, rutting and edge failure as considered by the study is as presented in Fig. 2. It presented the total surface area of pavement surface distress over the route length at Chainages measuring $4 \mathrm{~km}$ apart, starting from Zaria town on Chainage $\mathrm{CH} 003+000$ to Kaduna town on Chainage $\mathrm{CH} 059+000$. 


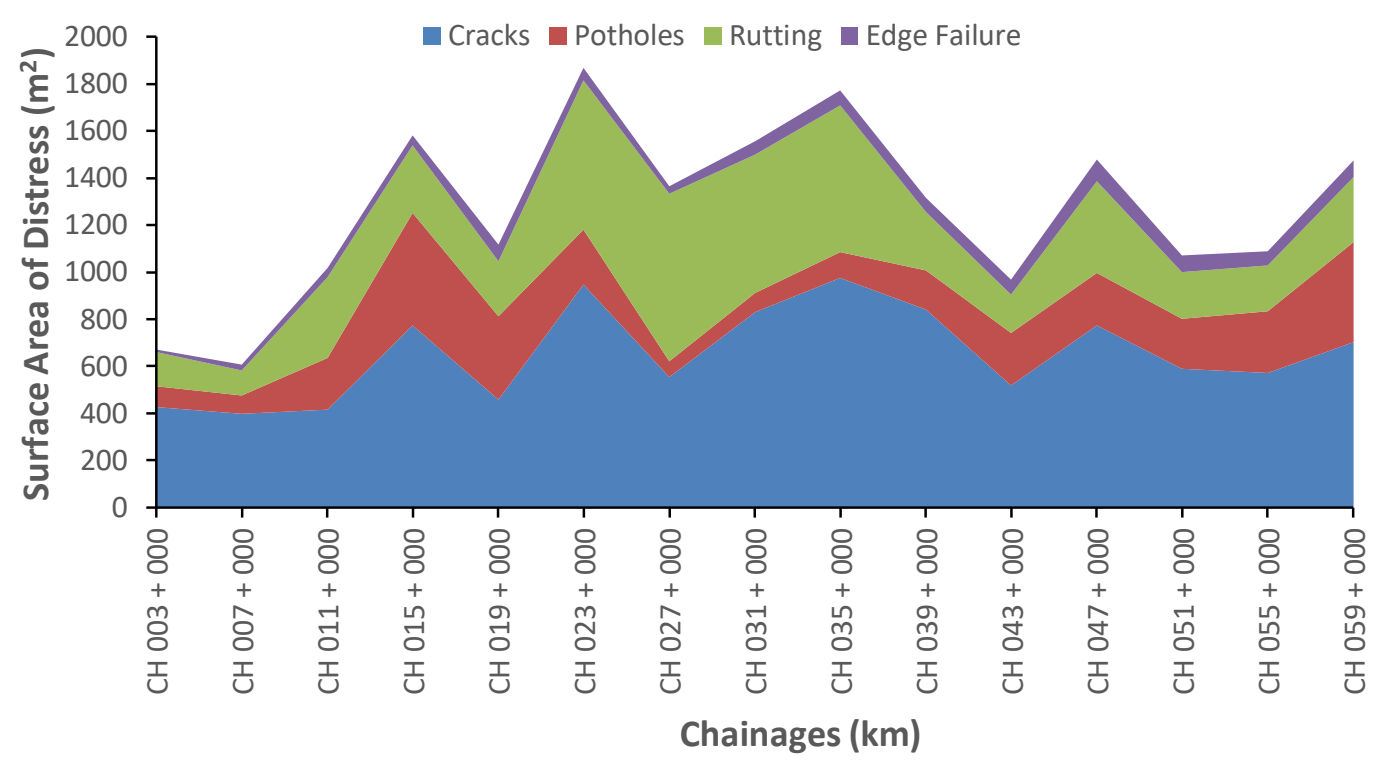

Figure 2. Magnitude of Distresses over Chainages

On the other hand, in line with findings of Park et al.[14] and Rahim [15], essential mechanical strength properties of subgrade soil that have correlation with the pavement surface condition are as presented in Table 1.

Table 1. Strength characteristics of subgrade materials

\begin{tabular}{|c|c|c|c|c|c|c|c|c|c|c|c|}
\hline $\begin{array}{c}\text { Chainages } \\
(\mathbf{k m})\end{array}$ & 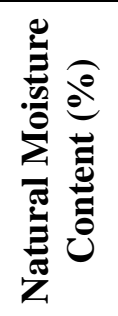 & 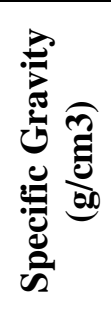 & 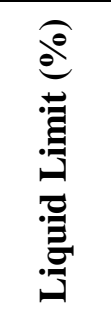 & 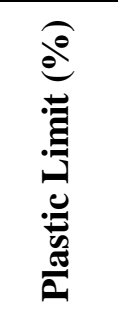 & 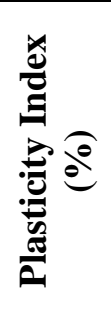 & 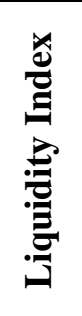 & 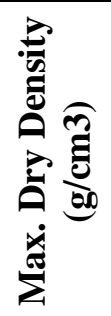 & فه & 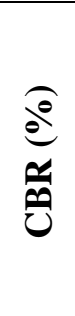 & 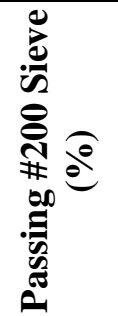 & 员 \\
\hline CH 000 & 10.5 & 2.695 & 39.0 & 27.6 & 11.4 & 2.5 & 11.7 & 1.98 & 13 & 38.0 & A-6(1) \\
\hline CH 003 & 10.4 & 2.663 & 32.7 & 20.9 & 11.8 & 1.9 & 12.5 & 1.95 & 14 & 46.0 & A-6(2) \\
\hline CH 007 & 11.0 & 2.715 & 35.2 & 22.2 & 13.0 & 1.9 & 13.3 & 1.93 & 18 & 49.4 & A-6(4) \\
\hline CH 011 & 13.0 & 2.673 & 36.0 & 25.2 & 10.8 & 2.1 & 13.7 & 1.93 & 34 & 38.3 & A-6(1) \\
\hline CH 015 & 10.7 & 2.680 & 35.4 & 24.5 & 10.9 & 2.3 & 13.2 & 1.93 & 25 & 44.5 & A-6(2) \\
\hline CH 019 & 11.0 & 2.754 & 35.4 & 26.0 & 9.4 & 2.6 & 12.5 & 1.95 & 16 & 25.7 & A-2-4(0) \\
\hline CH 023 & 12.5 & 2.714 & 37.2 & 27.5 & 9.7 & 2.5 & 13.7 & 1.91 & 30 & 27.4 & A-2-4(0) \\
\hline CH 027 & 9.5 & 2.656 & 38.3 & 24.0 & 14.3 & 2.0 & 14.4 & 1.88 & 13 & 44.5 & A-6(3) \\
\hline CH 031 & 12.0 & 2.752 & 40.4 & 27.0 & 13.4 & 2.1 & 15.2 & 1.87 & 20 & 42.7 & A-6(3) \\
\hline CH 035 & 11.0 & 2.727 & 41.6 & 28.5 & 13.1 & 2.3 & 13.1 & 1.91 & 22 & 42.4 & A-7-5(2) \\
\hline CH 039 & 10.2 & 2.701 & 40.0 & 27.2 & 12.8 & 2.3 & 14.1 & 1.88 & 18 & 34.6 & A-2-6(1) \\
\hline CH 043 & 10.0 & 2.741 & 40.0 & 29.0 & 11.0 & 2.7 & 12.3 & 1.94 & 31 & 31.7 & A-2-6(0) \\
\hline CH 047 & 10.6 & 2.616 & 38.4 & 29.7 & 8.7 & 3.2 & 14.3 & 1.91 & 29 & 24.1 & A-2-4(0) \\
\hline CH 051 & 11.0 & 2.578 & 39.1 & 29.3 & 9.8 & 2.9 & 15.1 & 1.89 & 17 & 32.7 & A-2-4(0) \\
\hline CH 055 & 11.5 & 2.607 & 44.2 & 30.0 & 14.2 & 2.3 & 16.2 & 1.77 & 8 & 75.2 & A-7-5(12) \\
\hline CH 059 & 10.5 & 2.595 & 46.4 & 33.6 & 12.8 & 2.8 & 15.9 & 1.83 & 18 & 41.0 & A-7-5(2) \\
\hline Max. & 13 & 2.75 & 46.40 & 33.6 & 14.30 & 3.2 & 16.2 & 1.98 & 34 & 75.2 & - \\
\hline Average & 10.96 & 2.68 & 38.71 & 27.01 & 11.70 & 2.4 & 13.8 & 1.9 & 20 & 39.9 & - \\
\hline Min. & 9.50 & 2.58 & 32.70 & 20.90 & 8.70 & 1.9 & 11.7 & 1.77 & 8.0 & 24.1 & - \\
\hline SD & 0.912 & 0.056 & 3.505 & 3.181 & 1.75 & 0.4 & 1.31 & 0.1 & 7.5 & 12.1 & - \\
\hline
\end{tabular}


Fig. 2 revealed that crakes and rutting defects were the most significant distresses that affected pavement surface condition of the highway along its route length. It also revealed that, there were relatively less effects of surface defects on the surface area of the road pavement from Chainages $\mathrm{CHOO3}+000$ to $\mathrm{CHOO9}+000$. This was attributed to the road rehabilitation by surface overlay of the highway carried out by the road maintenance agencies recently, twelve (12) months before the field survey was carried out.

Table 1 presented the distribution and descriptive statistic of mechanical properties as explanatory variables used for defining strength characteristics of the subgrade soils along the Zaria - Kaduna Federal Highway. It also revealed the natural moisture content of the subgrade soils to predominately fall between 10.00 and 13.00 with an average value of $10.96 \%$. This agreed with findings of Murana [9] for a stable subgrade soils for road construction in Northern Nigeria. It also agreed with requirements of the Nigerian specification for road construction [13]. Other explanatory variables such as Specific Gravity, Atterberg Limits (Liquid limit, Plastic limit, Plasticity index, Liquidity index) have all given specific descriptions of the subgrade soil along the route majorly as granular soils based on the AASHTO classification system [24]. The Maximum dry density values and the Optimum moisture content parameters yielded results that clearly justified the significant values of CBR obtained. The CBR values in which the resilient modulus depends on directly defines the structural strength of the subgrade soil, and it agreed with findings of previous studies by Murana [9]. The percentage passing \#200 sieve indicated that the subgrade soil is best classified as both coarse and fine grained soils at different Chainages since more than $35 \%$ of the soil particles retained on the \#200 sieve for the granular soils and less that $35 \%$ for the fine soils [25-27], with an average value of $40 \%$ approximately passing through the sieve. This partly satisfies the basic requirements of a good subgrade soil as specified in the Nigerian Specifications for Road and Bridges [13].

The distribution of average surface area covered by pavement distresses and corresponding structural strength characteristics of the subgrade soil denoted by the CBR values is presented in Fig. 3.

From Fig. 3, mechanical strength properties of the subgrade soil defined as its CBR value at Chainages $\mathrm{CH} 003+000$ to $\mathrm{CH} 009+000$ were low with corresponding low distressed surface area. This is also attributed to the overlay rehabilitation works carried out on the road segment shortly before the field work (within 1 year). Fig. 3 also revealed the significant variations between the CBR values and surface areas of distresses along the entire route length. 


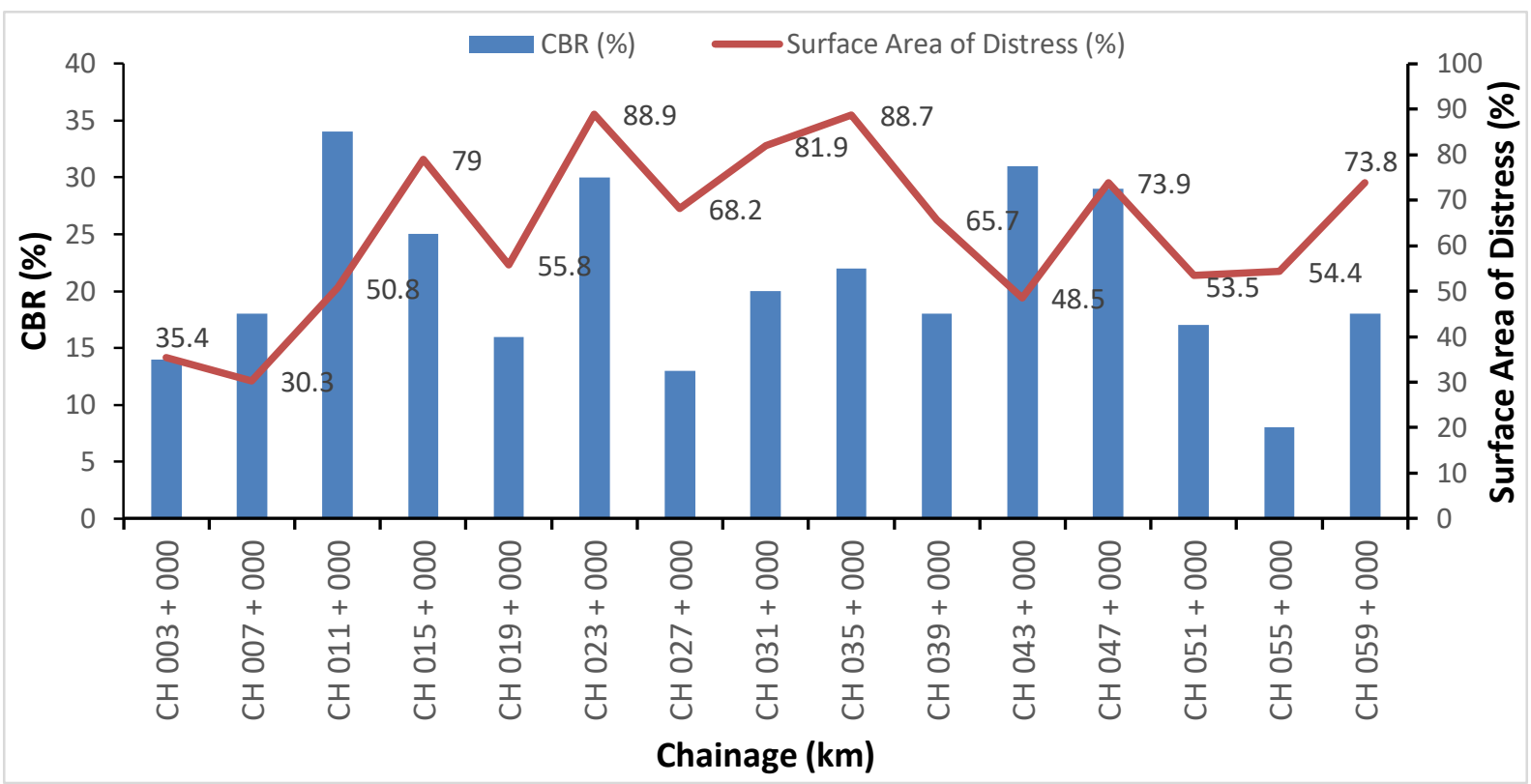

Figure 3: Relationship between CBR and Surface Area of Distress along Chainages

Though there was no quantitative measure of the differences between variables, Table 2 shows results of the Pearson Correlation (or Peakman's Moment Correlation) method of analysis between the CBR values of the subgrade soil and surface areas of defects within segments.

Table 2: Outputs of Correlation Analysis

\begin{tabular}{llrr}
\hline Variables & Parameters & CBR Value & Surface Area of Defects \\
\hline CBR Value & Pearson Correlation & 1 & 0.254 \\
& Significance (1-tailed) & & 0.180 \\
& Sum of Squares and Cross & 781.733 & 483.007 \\
& Products & & \\
& Covariance & 55.838 & 34.500 \\
& N & 15 & 15 \\
Surface Area & Pearson Correlation & 0.254 & 1 \\
of Defects & Significance (1-tailed) & 0.180 & 4619.517 \\
& Sum of Squares and Cross & 483.007 & 329.966 \\
& Products & & \\
& Covariance & 34.500 & 34.500 \\
& N & 15 & 15 \\
\hline
\end{tabular}

Table 2 revealed that the Pearson Correlation value between the variables is 0.254 . This indicated very weak correlation between the CBR values of the subgrade soil and the surface condition of the road pavement defined by defective surface area. This implied that, variations in strength properties of the subgrade soil have no significant impact on the degree of surface distress of the road pavement. In other words, there is no significant dependence of road surface distress on the strength or mechanical properties of the subgrade soil. Also, a test of statistical significance using a 1-tailed statistical hypothesis at 5\% level of significant to test for dependency between the CBR value and surface area of defects indicated that, there was no 
statistically significant correlation between the variables since the likelihood probability value of 0.180 is grater that 0.05 at $95 \%$ confidence interval. Hence the Null hypothesis $\left(\mathrm{H}_{\mathrm{o}}\right)$ was rejected and the Alternative hypothesis $\left(\mathrm{H}_{1}\right)$ accepted.

\section{CONCLUSION}

Due to the incessant deterioration of flexible road pavements on Federal Highways in Northern Nigeria, which in some quarters is attributed to poor structural capacity of the subgrade soil or design and workmanship, the study carried out an investigation and analysis of flexible road pavement surface condition and the corresponding structural capacity of subgrade soil along 60 km length Zaria - Kaduna Federal Highway in Northern Nigeria. Data on experimental results were obtained from the Federal Ministry of Power, Works and House Nigeria. A field survey was also carried out to obtain surface conditions of the flexible road pavement affected by distresses such as fatigue cracks, rutting or permanent deformation, edge failure, potholes and rutting. Mechanical properties of the subgrade soil such as; the natural moisture content, maximum dry density, specific gravity, liquid limit, plastic limit, liquidity index, plasticity index, optimum moisture content, California Bearing Ratio (CBR), percent passing \#200 sieve and AASHTO classification of the subgrade soil were examined. A correlation analysis between the road pavement surface condition and the CBR value of subgrade soil at Chainages revealed no dependency between the pavement surface condition and the corresponding strength properties of the subgrade soil at $95 \%$ confidence interval. Therefore, it could be concluded that, the surface condition of flexible road pavement on the sampled site in Northern Nigeria is not a direct function of the structural strength of the subgrade soil, which was possibly due to site specifics.

\section{Acknowledgements}

We are most grateful to the Federal Ministry of Power, Works and Housing Nigeria for providing some of the dataset used. We appreciate Mr. Richard Tyokyaa and Mr. Fater Tume for their immersed support in carrying out the field survey on the Zaria - Kaduna Federal Highway.

\section{References}

1. M. A. P. Taylor and M. L. Philip. Investigating the Impact of Maintenance Regimes on the Design Life of Road Pavements in a Changing Climate and the Implications for Transport Policy. Transport Policy, 41 (2015) 117-135. 
2. O. S. Abiola, A. O. Owolabi, S. O. Odunfa and A. Olusola. Investigation into Causes of Premature Failure of Highway Pavements in Nigeria and Remedies. In proceedings of the Nigeria Institution of Civil Engineers (NICE) Conference. (2010).

3. P. T. Adeke, A. A Atoo and S. G. Orga. Assessment of Pavement Condition Index: A Case of Flexible Road Pavements on the University of Agriculture Makurdi Campus. Nigerian Journal of Technology. 38:1 (2018) 15-21.

4. Road Sector Development Team. Configuration and Calibration of HDM-4 to Nigeria Conditions, Government of the Federal Republic of Nigeria. Nigeria. (2014) pp. 33.

5. N. J. Garber and L. A. Hoel. Traffic and Highway Engineering, $4^{\text {th }}$ Edition, Cengage Leaning, Canada. (2009).

6. G. Claros, R. F. Carmichael and J. Harvey. Development of Pavement Evaluation Unit and Rehabilitation Procedure for Overlay Design method. Lagos: Texas Research and Development Foundation for the Nigeria Federal Ministry of works and Housing, Nigeria. (1986).

7. F. Salour and S. Erlingsson. Resilient Modulus Modelling of Unsaturated Subgrade Soils: Laboratory Investigation of Silty Sand Subgrade, Road Materials and Pavement Design. 16:3 (2015) 553-568.

8. C.N.V.S. Reddy, N.V.R. Moorthy, Significance of Bearing Capacity of Clayey Subgrade in Flexible Pavement Design. The International Journal of Pavement Engineering, 6:3 (2005) 183-189.

9. H. Soliman and A. Shalaby. Characterising the elastic behaviour of fine-grained subgrade soils under traffic loading. International Journal of Pavement Engineering, 15:8 (2014) 698-707.

10. A. A. Murana. Characterisation of Subgrade Materials from Some Nigerian Sources for use in the Nigeria Empirical-Mechanistic Pavement Analysis and Design System, PhD Thesis, Department of Civil Engineering, Faculty of Engineering, Ahmadu Bello University Zaria, Kaduna State, Nigeria. (2016).

11. Y. H. Huang. Pavement Analysis and Design. Upper Saddle River: Prentice-Hall. (2004).

12. E. Sadrossadat, A. Heidaripanah, and B. Ghorbani. Towards Application of Linear Genetic Programming for Indirect Estimation of the Resilience Modulus of Pavements Subgrade Soils. Road Materials and Pavement Design. 19:1 (2016) 139-153.

13. H. S. Otuoze, Y. D. Amartey, A. Ocholi and A. A. Murana. Effectiveness of Corn Cob Ash (CCA) as Filler in Asphalt Concrete Design, Nigerian Journal of Engineering, Ahmadu Bello University Zaria, Kaduna - Nigeria, 18 (1) (2011) 32 - 39.

14. Federal Ministry of Works. Nigerian General Specifications for Roads and Bridges, Abuja, Nigeria. (2016).

15. H. M. Park, M. K. Chung, Y. A. Lee and B. I Kim. A study on the correlation between soil properties and subgrade stiffness using the long-term pavement performance data, International Journal of Pavement Engineering, 14:2 (2013) 146-153.

16. A. M. Rahim. Subgrade Soil Index Properties to Estimate Resilient Modulus for Pavement Design, The International Journal of Pavement Engineering, 6:3 (2005) 163-169.

17. J. A. Prozzi. Modeling pavement performance by Combining Field and Experimental Data. $\mathrm{PhD}$ Thesis, Civil and Environmental Engineering, University of California, Berkeley, USA. (2001). 
18. A. A Murana, A. T. Olowosulu and H. S. Otuoze. Minimum Threshold of Monte Carlo Cycles for Nigerian Empirical-Mechanistic Pavement Analysis and Design System. Nigerian Journal of Technology, 31:3 (2012) 321-328.

19. M. Elshaer, M. Ghayoomi and S. Daniel. Impact of subsurface water on Structural performance of Inundated Flexible Pavements. International Journal of Pavement Engineering. 20:8 (2017) 947-957.

20. J. M. Rasul, M. P. N. Burrow and G. S. Ghataora. Consideration of the deterioration of stabilised subgrade soils in analytical road pavement design, Transportation Geotechnics, 9 (2016) 96-109.

21. Google Earth. Google Map Int'l. (2019).

22. R. F. Craig. Craig's Soil Mechanics, $7^{\text {th }}$ Edition, London, United Kingdom. (2004).

23. ASTM D6433-07. Standard Practice for Road and Parking Lots Pavement Condition Index Survey, American Standard for Testing and Materials, Philadelphia. (2007).

24. BS 1377. Method of Testing Soils for Civil Engineering Purpose. British Standard Institute, BSI, London. (1990).

25. M. D. Braja. Principles of Geotechnical Engineering, $7^{\text {th }}$ Edition, Cengage Learning, Stamford, USA. (2010).

26. AASHTO. Standard Specification for Transportation, Material and Methods of Sampling and Testing. 14th Edition. Amsterdam Association of State Highway and transportation officials Washington D.C. (1986).

27. N. Venkatesh, M. Heeralal and R. J. Pillai. Resilient and Permanent Deformation behaviour of Clayey Subgrade Soil Subjected to Repeated Load Triaxial Tests, European Journal of Environmental and Civil Engineering. 24:9 (2018) 1414-1429. 